\title{
Construções coletivas em educação do campo inclusiva: reflexões sobre uma experiência na formação de professores
}

\author{
Juliana Crespo Lopes \\ Lucia Helena Cavasin Zabotto Pulino' \\ Mariana Barbato' \\ Regina Lucia Sucupira Pedroza'
}

\section{Resumo}

A educação do campo é resultado de um processo de transformação de valores e práticas na sociedade civil na forma de política do movimento social do campo. Neste artigo, exploramos a proposta de uma educação do campo inclusiva através de uma pesquisa realizada em um curso de formação de professores sobre o tema. A educação do campo se apresenta como um espaço aberto para trabalhar ideias sobre educação inclusiva, uma vez que pauta suas práticas em uma educação que saia dos moldes tradicionais e que valorize os sujeitos envolvidos. 0 trabalho de formação de professores realizado foi pautado em práticas reflexivas sobre o tema, em quatro encontros para uma pesquisa de mestrado de uma das autoras. Para este artigo, optamos por analisar as discussões e falas que emergiram durante o segundo encontro, uma vez que este foi o início do processo de construção de um espaço reflexivo aberto a possibilidades. A reflexão de futuros educadores sobre as questões com as quais irão lidar em sala de aula apareceu como um ponto bastante interessante para que seja realizada uma construção coletiva em cursos de licenciatura em educação do campo e se elabore uma possibilidade real e contextualizada de uma educação do campo inclusiva.

\section{Palavras-chave}

Formação de professores - Educação do campo - Práticas reflexivas Educação inclusiva.

I- Universidade de Brasília, Brasília, DF, Brasil. Contatos: juliana.jc|@gmail.com; luciahelena.pulino@gmail.com; barbat009.mariana@gmail.com; rpedroza@unb.com 


\title{
Collective construction of rural inclusive education: reflections on an experience in teacher education
}

\author{
Juliana Crespo Lopes \\ Lucia Helena Cavasin Zabotto Pulino' \\ Mariana Barbato' \\ Regina Lucia Sucupira Pedroza'
}

\begin{abstract}
Rural education is the result of the transformation of values and practices in civil society presented as a policy of the rural social movement. In this paper, we explore the proposal of inclusive rural education based on a study conducted in a teacher education course on that topic. Rural education is an open space to work on inclusive education ideas, since its practices are guided by a nontraditional model of education that values the subjects involved in the process. This teacher education work was guided by reflection on the topic in four meetings conducted for the Master's research of one of the authors. In this article, we analyze the discussions and discourses of the second meeting, since it was the beginning of the construction of a reflective space open to possibilities. The reflection of future educators on issues that they will deal with in classroom appeared as a very interesting point for collective construction in undergraduate courses in rural education and for a real and contextualized possibility of inclusive rural education.
\end{abstract}

\section{Keywords}

Teacher education - Rural education - Reflective practices Inclusive education.

I- Universidade de Brasília, Brasília, DF, Brasil. 
A educação do campo se caracteriza como um espaço inovador em relação à educação rural, inaugurando uma postura ética e política que, em sua construção coletiva, nos permite repensar práticas escolares e de formação de professores. Considerando as dificuldades vividas por professores tanto nas escolas urbanas quanto nas escolas do campo e a carência de produções acadêmicas ou reflexões sobre práticas escolares que abordem uma educação inclusiva, tornam-se necessárias pesquisas que envolvam esse assunto no contexto da educação do campo.

A educação para a população rural foi mencionada pela primeira vez em legislações brasileiras no artigo 28 da Lei de Diretrizes e Bases da Educação, que versava sobre as adaptações necessárias à educação naquele contexto. Atualmente, a educação do campo é regida pelo Decreto $n^{\circ} 7.352$, de 4 de novembro de 2010, que dispõe sobre a política de educação do campo e o Programa Nacional de Educação na Reforma Agrária. Ao falar sobre a educação do campo, Santos (2012) afırma que esta é resultado de um processo de transformação de valores e práticas da sociedade civil na forma de política do movimento social dos e para os camponeses. A autora elenca três grandes desafios para essa educação: assegurar aos camponeses o direito de acesso ao conhecimento, de modo a instrumentalizá-los para romper com sua histórica condição de subordinação frente ao capital; assegurar o direito à diferença, com o reconhecimento de suas práticas e conhecimentos produzidos; e, por fim, romper com o paradigma hegemônico do capital, por meio de um projeto que elabore e dissemine conhecimentos que são fruto de sua cultura.

Em contraposição à educação rural, a educação do campo busca responder às demandas das diferentes comunidades que a compõem como os quilombolas, os povos indígenas, as variadas formas de trabalhadores e trabalhadoras do meio rural e os camponeses. A educação rural é uma prática escolar conduzida por organismos oficiais, propagando o ideário de produção capitalista e que busca adaptar os sujeitos do campo a essa produtividade, bem como exaltar o modo de vida urbano (OLIVEIRA; CAMPOS, 2012). Relaciona-se ainda com a escolarização fornecida pelos proprietários das terras ou com a total falta de possibilidades de educação, sem responsabilidade por parte do Estado em prover uma educação pública e de qualidade para todos.

Entendemos que uma educação de qualidade contempla as demandas de toda a comunidade escolar no que diz respeito tanto a aspectos do ensino formal e sua estrutura necessária até o acolhimento social e emocional de seus participantes como sujeitos de direitos e desejos. Além dessa complexidade em abarcar diferentes contextos sociais, culturais e geográficos, a educação do campo envolve questões de cunho político, e, em especial, de empoderamento, no sentido de seus atores se tornarem sujeitos ativos e autônomos na práxis de suas decisões.

De acordo com Caldart (2012), a designação traz a consciência de mudança, uma vez que a educação do campo é resultado de uma luta dos trabalhadores desse meio para assegurar acesso a uma educação que seja feita pelos e para os camponeses. Ainda segundo a autora, as organizações sindicais que idealizam e constroem essa forma de educar são grupos de luta e protagonismo em busca constante por seus direitos. Esses grupos, com forte presença identitária e bandeiras que visam a conquistas próprias que justificam a educação do campo, vivenciam dentro do processo pedagógico desafios que se assemelham aos enfrentados pelas escolas urbanas no sentido de perpetuar práticas tradicionais de ensino que são discriminatórias e excludentes para uma parcela desse grupo que destoa da normatividade imposta. Tal fato se coloca como mais um desafio para que a educação do campo mantenha a estreita relação com a vida concreta, com o campo, seus habitantes, seus ideais e posturas. É a partir de uma construção realizada por esses sujeitos que a 
educação do campo se constitui por e para seus integrantes, possibilitando uma transformação nas concepções de escola e trazendo elementos fundamentais para que a sociedade como um todo se direcione para um caminho que abarque os direitos dos cidadãos do campo.

A práxis da educação e da escola do campo tem uma possibilidade real de modificar suas estruturas justamente por ser caracterizada como práxis: uma prática social transformadora, em que teoria e prática não se dissociam. Podemos perceber essa vinculação em Caldart (1997), pela maneira como a educação nos espaços do MST foi e continua sendo conduzida. Consiste em uma educação que tem em sua base uma preocupação de formação também política, uma participação coletiva derivada de situações práticas e direcionada para as mesmas, num processo inclusive de elaboração de conhecimento teórico inovador. É na experiência e no cotidiano que se pautam os conhecimentos que são produzidos, registrados, refletidos, colocados em prática e levados à reflexão, sempre para novas produções e registros. A educação do campo cria o cenário em que quer se desenrolar, ressignificar o mundo da educação e criar seu próprio espaço existencial.

0 processo de repensar e construir uma educação desvinculada daquela existente nas escolas urbanas tradicionais pode ser uma abertura para que sejam inseridas práticas de educação inclusiva nesses espaços. Entendemos a educação inclusiva como uma nova maneira de se ver e fazer a escola, na qual todos os envolvidos se beneficiam de mudanças estruturais, pedagógicas e filosóficas. Uma escola que pratica o respeito a todos, que trabalha a partir de uma ótica multicultural, que vê riqueza nas diferenças, nas complementaridades, se torna um ambiente que oportuniza importantes aprendizagens e um desenvolvimento humano valioso.

Optamos por utilizar a nomenclatura educação inclusiva no lugar da expressão inclusão escolar, mais comumente usada, porque entendemos o segundo como um acontecimento passivo: a escola permanece como está, ela não se modifica para que a inclusão - o ato em si - aconteça (ou tente acontecer). Enquanto que, ao se trabalhar com a proposta de uma educação inclusiva, colocase na educação a necessidade de se transformar, de se tornar uma nova educação, uma educação que é inclusiva, de todos e para todos.

Assim, considerando que a educação do campo é um espaço que busca e possibilita a consciência e a vontade de transformação, que traz em suas origens uma nova visão de mundo, de educação e de escola, seu contexto histórico, de lutas políticas e sociais, buscando sempre a garantia de direitos, abre-se caminho para se pensar em educação do campo inclusiva, com a inclusão sendo algo intrínseco a ela. Buscar uma transformação na educação que implique mudanças na sociedade de maneira mais ampla e garantir uma educação inclusiva através de acesso e permanência de todos na escola são ações que fazem parte da educação do campo. É possível, ainda, que nesse contexto seja mais fácil construir e colocar em prática uma educação inclusiva que de fato oportunize a todos os estudantes espaços de desenvolvimento cognitivo, social e emocional, uma vez que já se parte do princípio de que a estrutura escolar deve ser reformulada. A força de transformação daqueles que já são excluídos de tantas esferas de nossa sociedade pode em muito contribuir para as políticas de educação inclusiva em um país que já produziu muitas desigualdades dentro e fora das salas de aula.

\section{Práticas em formação docente para a inclusão}

Pensando nas especificidades de uma formação de professores para a educação do campo e na importância de se trabalhar a respeito da educação inclusiva naquele espaço, defendemos uma prática pedagógica baseada na educação popular e que apresente uma prática política, coletiva e emancipadora. Freire (2007) 
concebe uma educação na qual o educando desempenha uma atitude ativa em relação à sua produção de saber, colaborando para a construção e produção do conhecimento. 0 autor critica a pura transmissão de conteúdos na escola, denominada por ele de educação bancária, por suprimir a criatividade e a curiosidade do educando no ato de aprender, construir e problematizar o conhecimento de forma autônoma. A concepção de que não é possível utilizar um único método para diferentes pessoas, com características diversas de aprendizagem e distintos contextos de vida, é de suma importância na reformulação e transformação da educação e da sociedade como um todo.

Freire (2001, p. 60) coloca que:

0 que venho propondo é um profundo respeito pela identidade cultural dos alunos e das alunas - uma identidade cultural que implica respeito pela linguagem do outro, pela cor do outro, o gênero do outro, a classe do outro, a orientação sexual do outro, a capacidade intelectual do outro; que implica a habilidade para estimular a criatividade do outro.

Marques (2007) considera que a escola popular construída por Paulo Freire revela fundamentos de uma escola inclusiva, uma vez que assegura a permanência do aluno na instituição de ensino e se compromete com o aspecto global da qualidade na educação, assegurando que haja um desenvolvimento integral e não apenas cognitivo. A partir dos escritos freirianos, podemos assumir a importância de se construir uma possibilidade de inclusão escolar para cada instituição de ensino. Falamos em construir uma possibilidade, pois, como fica claro na obra de Paulo Freire, não existe uma única resposta, abordagem ou método que sejam adequados para que todos os educandos sejam incluídos na escola. Estar atento às singularidades dos sujeitos envolvidos e às subjetividades que compõem e constroem o meio escolar é de suma importância para que a inclusão exista e se consolide.

Uma prática de formação de professores a partir das propostas de Paulo Freire necessita que haja construção de um espaço de vivência onde se possa exercitar a problematização, a reflexão, a tomada de consciência e o diálogo em uma perspectiva de trocas de ideias e experiências que possam sensibilizar os educadores para uma nova prática educativa inclusiva. Na formação de professores, em geral, observa-se que não existe diálogo com as práticas dos professores, portanto, estas ficam inalteradas, conforme afirma Furlanetto (2011). A autora ainda defende que, ao invés de se ancorar na teoria, a formação de professores deveria se instalar no espaço entre a teoria e a prática, considerado como um espaço da dúvida e ausência de respostas para as questões que surgem no processo educativo. Araújo (2011) chama a atenção para o fato de que a universidade tende a centralizar o espaço de produção do conhecimento nela mesma. A autora sugere que se produza conhecimento em conjunto com a escola e com as professoras, ao invés de pesquisar sobre a escola e sobre as práticas docentes de forma distanciada.

Sobre a importância de superar a prática pedagógica tradicional, Martins (2014) critica a formação restrita ao conteúdo das disciplinas e às metodologias pré-determinadas, que ele chama respectivamente de saber e saber-fazer. 0 autor defende que sejam introduzidas

[...] outras dimensões no processo, aquelas relativas às experiências, às subjetividades, ao vivido, às relações humanas, novas perspectivas se abrem para o processo de formação, especificamente em sua intencionalidade, pois as preocupações não recaem mais somente sobre um saber ou saber-fazer, mas sobre o saber-ser, sabertornar-se. (MARTINS, 2014, p. 473).

Tomando emprestada a expressão freiriana quefazer, que pode ser entendida 
como o resultado da ação combinada à reflexão em uma promoção de transformações, Martins (2014) sintetiza seu pensamento explanando sobre a importância de um quefazer pedagógico que dê espaço para implicações, alterações, subjetividades, vivências e vicissitudes. Ao ir além do fazer pedagógico, defendendo um quefazer e, mais ainda, um quefazer que parte de vivências, subjetividades e vicissitudes, o autor abre espaço para uma prática de acolhimento dos professores em formação.

Da mesma forma, em uma crítica baseada em Foucault sobre as relações de saber-poder e a maneira como os conhecimentos são produzidos, Aguiar (2012) ressalta a importância do saber dos afetos no lugar de uma busca pela verdade, de um conhecimento estável. Novos saberes são construídos e novas possibilidades desenhadas a partir de indagações, reflexões e trocas. É nos movimentos de resistência, no diálogo e nas relações que são produzidos saberes.

\section{Unindo a prática de educação inclusiva à de educação do campo}

Os cursos de formação de professores para educação do campo são voltados para alunos provenientes do meio rural, como os do Movimento dos Trabalhadores sem Terra e das comunidades quilombolas. Esses espaços têm em comum uma característica bastante importante para a definição de sua identidade coletiva: são espaços de resistência e de luta. Assim, seja na esfera política, econômica ou educacional, existe uma postura diferenciada, que os possibilita percorrer um caminho que se distancia dos modelos padronizados da sociedade urbana capitalista em que estamos inseridos. Tendo em conta tal fato, evidenciase a difıculdade e a contradição de que uma pessoa ou instituição proveniente do contexto urbano capitalista possa ou deva determinar a maneira como as escolas do campo devem agir em situações como a educação inclusiva.
As diretrizes educacionais brasileiras (BRASIL, 2001a; 2001b; e 2013) partem de uma visão de educação inclusiva que mantém serviços de atendimento especializado. Essa concepção pode até mesmo dificultar a concretização da inclusão escolar, uma vez que muitos professores não se vêm como responsáveis pelo desenvolvimento de estudantes que são caracterizados como pessoas com deficiência. Esses serviços incluem profissionais com formação específica e equipamentos que viabilizam a acessibilidade de estudantes a materiais de aula e tecnologias assistivas. A falta de disponibilidade dessa estrutura em áreas como o campo, periferias e outras regiões do país acarreta dificuldades para a efetivação de uma educação inclusiva, uma vez que tais serviços são a base das diretrizes educacionais no Brasil.

Ao discorrer acerca da formação de professores para uma educação inclusiva, diversos autores (COELHO, 2010; FURLANETTO, 2011; ARAÚJO, 2011; BRAÚNA, 2011) citam a necessidade de partir da realidade da escola, das vivências dos professores e de aliar a teoria com a prática, realizando um processo mais contextualizado e significativo para os professores. A construção conjunta de conhecimentos e possibilidades é fundamental aqui, porque a intenção é oportunizar uma educação inclusiva mesmo em espaços onde não existam os recursos que as diretrizes educacionais preveem.

Universidades federais brasileiras têm criado e mantido nos últimos anos cursos de licenciatura em educação do campo (LEdoC), para formar profissionais que irão trabalhar no segundo ciclo do Ensino Fundamental nas escolas do campo. A presente pesquisa foi realizada em um desses cursos. Partindo das concepções freirianas de educação e considerando as bases da educação do campo, percebemos que o trabalho proposto com os estudantes do LEdoC deveria ser realizado de forma coletiva, a partir dos conhecimentos e vivências em suas comunidades. De acordo com seu Projeto Político Pedagógico, o LEdoC tem, entre seus 
objetivos, realizar uma "construção coletiva de um projeto de formação de educadores que sirva como referência prática para políticas e pedagogias de educação do campo" (UNB, 2009, p. 3). Essa visão de construção coletiva torna o LEdoC um espaço que tem em sua base uma visão que percebe o outro também como produtor de conhecimentos.

A construção de estratégias pedagógicas passa pela emergência dos sentidos subjetivos que serão mobilizados a respeito do tema quando se fala sobre ele. Partindo das concepções expostas por González Rey (2007), entendemos sentidos subjetivos como uma unidade psicológica que integra processos emocionais e simbólicos produzidos em diferentes experiências, sobre definições de determinada cultura. São produzidos por meio da ação do sujeito e se organizam em configurações subjetivas que delimitam os limites e potencialidades que serão próprios da subjetividade, sistema gerador, criativo e singular. Os sentidos subjetivos devem ser entendidos em uma processualidade que envolve as relações e a organização social em que a pessoa vive e que a pode levar, em seu processo de tornar-se sujeito, a subverter o que é simplesmente dado pela cultura, "implicando sua ação no compromisso tenso e contraditório de sua subjetividade individual e da subjetividade social dominante" (GONZÁLEZ REY, 2007, p. 135).

Sendo assim, o presente artigo tem como objetivo refletir sobre a construção de estratégias pedagógicas visando a uma educação do campo inclusiva, realizadas conjuntamente entre estudante do LEdoC e pesquisadoras da área de psicologia.

\section{O espaço Aion como prática metodológica}

Esta pesquisa teve como orientação teórico-metodológica a epistemologia qualitativa de González Rey (2005) articulada com ideias e práticas construídas e desenvolvidas pelo espaço Aion (PULINO, 2007; 2009). 0 projeto de extensão Espaço de reflexão, prática em filosofia, artes e humanidades: Espaço Aion (PULINO, 2007; 2010; 2011), da Universidade de Brasília, constitui-se como um espaço de diálogo e reflexões que assume uma noção de tempo diferenciada, como indica o próprio nome. Conforme o filósofo pré-socrático Heráclito, no fragmento 52, aion é o tempo da criança criançando (COSTA, 2002), o tempo do acontecimento, um tempo não mensurável, em oposição a chronos, o tempo cronológico.

Tomando-se essa referência, já se delimita que o espaço Aion consiste num espaço / tempo de experiência, de troca não apenas de ideias, de reflexão, mas de afeto, de ações conjuntas. Nesse espaço são realizadas oficinas, onde não se espera que as pessoas ajam de modo prédeterminado, dando respostas rápidas e corretas, mas que expressem suas ideias, sentimentos e ações como sujeitos, autores, isto é, que se coloquem na primeira pessoa. Dessa forma, não se espera um resultado da conversa do grupo, mas, sim, o desenrolar do processo mesmo de construção de discursos que se articulam, por concordância ou discordância, sempre permeados de afeto. Permite-se que se desenhem caminhos e momentos, de modo que seja possível compreender o movimento da participação das pessoas que fazem parte do grupo em relação a assuntos tematizados no início, por meio de um pretexto, ou texto motivador, ou que surjam durante a oficina (PULINO, 2007).

Pela participação conjunta, constroem-se reflexões e posicionamentos em relação ao tema escolhido. Essa dinâmica de discussão, em que todas as vozes têm espaço, vai ao encontro das ideias de Freire acerca do processo educativo, que deve levar em consideração a singularidade subjetiva de cada estudante que compõe o grupo de reflexão. Nesse contexto, promove-se a construção conjunta do processo educativo em que as pessoas atuam enquanto sujeitos, que segundo González Rey (2005), são indivíduos implicados de forma constante em suas práticas, reflexões e sentidos subjetivos, intervindo através de sua processualidade reflexiva nos espaços sociais, sendo também constituídos por estes. 
0 espaço / tempo experienciado em cada encontro aiônico por meio de materiais motivadores, os chamados pretextos, que convidam à reflexão e às trocas intersubjetivas, vai ao encontro do que González Rey (2005) define como processo essencial para a condição de constituição e emancipação do sujeito, que é a ruptura dos limites impostos pelo contexto social, pelas tendências dominantes, para que as pessoas possam ir modificando esses limites e gerando novas opções de participação na trama social em que atuam, por meio da construção de caminhos que acessem novas zonas de sentido dessa trama, num processo que implica responsabilidade e afeto.

As concepções educativas de Paulo Freire, a visão de sujeito de Gonzáléz Rey e os procedimentos inspirados na prática-teórica do espaço Aion podem se constituir como um processo rico e produtivo de práticas pedagógicas inovadoras e inclusivas no contexto da formação de professores. Dar voz ao professor em formação pode possibilitar que essa abertura também aconteça em suas salas de aula, promovendo processos de ensino e aprendizagem interessantes, inclusivos e acolhedores.

Em um viés epistemológico, o conhecimento produzido em espaço coletivo, com a participação de futuros professores - ou mesmo professores em formação continuada - pode se configurar como um saber crítico, contextualizado em sua realidade, que amplie suas reflexões sobre as condições sociais em que se encontram, de modo que possam implicarse com responsabilidade e afeto nas mudanças desejadas para o meio social do qual fazem parte.

A partir do que foi colocado acima, no contexto da pesquisa aqui relatada, as informações foram construídas por meio de oficinas inspiradas no trabalho teóricoprático do espaço Aion. Elegeu-se como orientação do percurso de pesquisa, análise e compreensão das informações construídas a perspectiva cartográfica, que assume a pesquisa como investigação e intervenção, incluindo participantes e pesquisadores no processo.

\section{Caminhos para a análise}

Nessa perspectiva, uma visão inspirada no método cartográfico auxiliou o processo de construção de um contexto para proporcionar reflexão sobre temas relacionados a uma educação do campo inclusiva. A partir da base cartográfica proposta por Deleuze e Guattari (PASSOS; KASTRUP; ESCÓSSIA, 2009; DELEUZE; GUATTARI, 2008; GUATTARI; ROLNIK, 2005), que compreende e analisa o processo, no lugar de buscar objetivos previamente estipulados, foi desenvolvido um espaço de reflexão sobre a questão, envolvendo também as pesquisadoras. Tal perspectiva de construção conjunta é amparada por estudos que utilizam a cartografia de Deleuze e Guattari, uma vez que, como bem sustenta Romagnoli (2009), o pesquisador cartógrafo, que constitui também seu meio de pesquisa, deve atentar e mapear relações, conexões, marcas e estratos para buscar conhecer a realidade pesquisada em sua complexidade.

Passos, Kastrup e Escóssia (2009) ressaltam que a cartografia não é um método prescritivo, com protocolos e instruções dados a priori, e assumem o caráter provisório, instável e parcial das pesquisas. Essa compreensão da pesquisa como um processo, como um devir contínuo, é essencial no caso aqui trabalhado, uma vez que entendemos que a educação - e mais, em nossa concepção, a educação inclusiva - deve estar em constante reformulação. Esse processo deve ser construído por aqueles que o integram, sendo renovado diariamente, tanto em ações quanto em ideias. Por se tratar ainda um assunto bastante recente e sem políticas e práticas definidas por organismos externos, faz-se necessário, portanto, realizar seus passos iniciais partindo de seu contexto, seu povo e seu modo de pensar. E é para tal fim que se propõem oficinas que se destinam a buscar dar início, a partir de dispositivos que fomentem reflexão e construção, ao que poderá se constituir como uma educação do campo inclusiva.

Passos e Benevides (2009) destacam que é imprescindivel considerar a inseparabilidade 
existente, na visão cartográfica, entre pesquisar e intervir, do que decorre que toda pesquisa é intervenção. As autoras defendem ainda que o caminho da pesquisa-intervenção é um caminhar com o objeto, constituir e constituir-se no caminho de sua construção. A intervenção tem, assim, um caráter político, uma vez que não se busca a representação do objeto, mas sim trabalhar a partir de uma compreensão que percebe a realidade sendo transformada, com a participação de todas as pessoas envolvidas, inclusive do pesquisador.

Esses diferentes olhares que vão além da esfera de saberes estritamente teóricos da educação e da psicologia estão perpassados por identidades e culturas específicas na constituição subjetiva de cada participante dessa construção. 0 que permite esse diálogo é a identidade dos estudantes com as questões da educação do campo.

A análise e a compreensão das informações construídas durante a pesquisa seguem uma inspiração cartográfica, uma vez que a cartografia traz em seu bojo a compreensão acerca dos processos de subjetivação, que se constituíram como foco das oficinas realizadas. Os espaços de construção de conhecimento são concebidos a partir da compreensão de que os indivíduos e os coletivos, por meio de seus processos de subjetivação, constroem e transformam seus espaços e suas sociedades. Ao trabalharmos a partir de uma perspectiva de inspirações cartográficas, estamos assumindo um papel de pesquisadoras conscientes, com uma postura ética, estética e política, que observam e buscam refletir sobre os percursos e processos vividos e experienciados na pesquisa.

\section{Método}

Contexto: curso de licenciatura em educação do campo (LEdoC) da Universidade de Brasília (UnB).

Participantes: quarenta estudantes de um curso de LEdoC, pertencentes a uma mesma turma que cursava disciplina sobre desenvolvimento, aprendizagem e práticas pedagógicas. Duas pesquisadoras da área de psicologia do desenvolvimento e aprendizagem. (IP/UnB).

Instrumentos: foram utilizados como pretextos da oficina fragmentos de textos e imagens relacionados ao contato de professores com a necessidade da educação inclusiva; à iniciativa bem-sucedida de uma professora em realizar educação inclusiva em sala de aula; e à crítica a um modelo educacional preconceituoso ou padronizador da subjetividade dos estudantes, com o objetivo de motivar os discursos e diálogos que se seguiram em torno das experiências dos participantes em relação ao tema da educação inclusiva e das possibilidades de construção de estratégias pedagógicas que articulassem a educação inclusiva à educação do campo.

As diversas questões e perspectivas em torno dos temas foram sinalizados em quadro-negro.

As pesquisadoras utilizaram gravadores e diário de campo para a construção da análise e reflexão sobre a complexidade da realidade pesquisada.

Procedimentos: a partir da apresentação do trabalho de uma das pesquisadoras no LEdoC, surgiu a demanda para a realização de atividades que abordassem a questão da inclusão escolar e da educação especial em uma disciplina de psicologia dentro do curso. Foram realizados nesse momento cinco encontros a partir dos quais um projeto de pesquisa foi construído para trabalhar com uma nova turma.

Para a pesquisa, foram realizados quatro encontros em formato de oficinas reflexivas, como no espaço Aion, com a turma, pautando-se na concepção de uma construção coletiva de possibilidades de educação inclusiva no espaço da educação do campo, tendo como foco o processo desta construção. Iremos aqui trabalhar e aprofundar as situações construídas no segundo encontro, por ter possibilitado uma abertura para o diálogo e a emergência de conteúdos que 
ilustram a discussão acerca do processo de construir possibilidades educacionais para o contexto específıco da inclusão, em conjunto com a população desse espaço.

Os encontros foram planejados no sentido de promover, problematizar e repensar as posturas e os modos de ver, lidar e entender a educação inclusiva a partir dos contextos e vivências dos envolvidos. Nosso propósito com isso foi possibilitar a construção de estratégias pedagógicas, entendidas não apenas como concretização de instrumentos, mas também - e principalmente - de uma disposição subjetiva para lidar com o tema. Entendemos esse termo como uma abertura para experienciar o processo, ponto fundamental para as reflexões que propomos.

\section{Relato e análise}

Como pretexto inicial, foi proposta a leitura de textos informais escritos por professores que se depararam com a questão da inclusão escolar em suas salas de aula. A partir da leitura e posterior debate em pequenos grupos, foram elencadas algumas questões que se pautaram no compartilhamento das experiências de cada um com o tema, em críticas, dúvidas e inseguranças sobre a possibilidade de realizar uma educação inclusiva nas escolas do campo. As reflexões suscitadas a partir das questões levantadas foram bastante significativas no que concerne à compreensão e produção de conhecimento nas áreas de formação de professores e de inclusão escolar, uma vez que a oficina proporcionou uma abertura para que se falasse a partir de uma ótica experiencial, crítica e verdadeira, aproximando-se do modo singular como os educadores do campo produzem conhecimento teórico inovador: partindo de uma participação coletiva derivada de situações práticas e direcionada para as mesmas, como explicita Caldart (1997).

Vale ressaltar que o teor crítico das falas está relacionado a um percurso histórico - tanto de grupo quanto individual - marcado por omissão por parte do Estado e de outras parcelas da sociedade, o que construiu uma identidade de luta com base em um saber político e econômico que busca modificar as estruturas vigentes em prol dos direitos e desejos das populações do campo (CALDART, 2012). Consideramos que uma visão crítica colabora para a construção de algo novo, uma vez que um dos aspectos do posicionamento crítico é a insatisfação com a situação presente. A maneira como o encontro foi realizado tinha o propósito de mobilizar os participantes em relação ao assunto, levá-los a debater e a refletir sem que houvesse uma linha de raciocínio ou comportamento a ser seguido. Aliando-se à visão crítica que já faz parte da formação dos educadores do campo, o espaço Aion (PULINO, 2007; 2009) se constituiu como espaço possível para o compartilhamento de pontos de vista críticos, indo além, como contexto propício à reflexão e à tomada de consciência dos participantes de serem sujeitos capazes de ações promotoras de mudança. Nesse sentido, a necessidade de implicação afetiva dos participantes, tanto no processo de compartilharsuas experiências, quanto no de acolher as experiências do outro, em um contexto de construção e não de resolução, possivelmente colabora para o processo de assegurar o direito à diferença e ampliar a disseminação de conhecimentos que são próprios da cultura do campo, pontos que foram indicados por Santos (2012) como desafios a esta forma de pensar a educação.

Buscou-se romper com a rotina de funcionamento de uma sala de aula, trabalhando-se sem a definição de papéis a serem desempenhados, tanto por se partir do princípio de que as metodologias de ensino precisam ser modificadas a fim de envolver os estudantes em seu processo de aprendizagem, quanto por compreender que os conhecimentos disseminados nas instituições de ensino e em específico acerca do tema de uma educação inclusiva no campo devam ser construídos conjuntamente. Essa abordagem para a realização da pesquisa oportunizou a expressão de medos, ansiedades, desejos e opiniões favoráveis e contrárias sobre a educação inclusiva, principalmente em relação à formação de professores e à estrutura necessária 
para tal. Utilizando uma abordagem sensível à necessidade de reconhecimento e emergência da identidade cultural e da singularidade dos participantes (FREIRE, 2007) na reflexão e construção de estratégias educacionais para lidar com a inclusão, observamos o início de um processo de autoimplicação, responsabilidade e afeto na co-construção de posicionamentos em relação ao tema, condição necessária para a emancipação do sujeito e geração de novos sentidos subjetivos (GONZÁLEZ REY, 2005) que possibilitam a ocorrência de inovações nas estratégias pedagógicas.

\section{O processo de construção do novo}

As questões iniciais formuladas pelos pequenos grupos giraram em torno de um dualismo entre as dificuldades de se realizar uma educação inclusiva e a importância de colocá-la em prática. As frases levantadas pelos grupos a partir da discussão foram as seguintes:

1 - Necessidade de mudar mentalidade.

2 - Professor conseguiu sem preparo nenhum fazer a criança aprender. Mas, na realidade, não é sempre assim, né?

3 - Quais os benefícios e malefícios da inclusão em uma sala superlotada?

4 - Até que ponto nossa sociedade entende que é normal ser diferente?

5 - Todos nós temos dificuldades para trabalhar com pessoas com deficiência.

6 - É difícil, mas não é impossível. A gente tem que buscar.

7 - Construção coletiva a partir de troca de experiências, "amor ao que faz".

A partir dessas frases, os estudantes selecionaram a terceira e foi então realizada uma grande discussão em um processo de reflexão e de construção conjunta por meio de um diálogo que envolveu articulação, defesa e análise de posturas e compreensões de mundo que abarcam a educação do campo inclusiva. A crítica em relação à viabilidade dessa educação esteve presente, principalmente porque o viés de compreensão de inclusão em que se pautaram estava bastante preso à deficiência. Além disso, existiram várias críticas e questionamentos em relação às exigências do Estado que não eram compatíveis com a infraestrutura disponivel, principalmente no que concerne à formação de professores e à existência de profissionais especializados (COSTA, 2008). Ao final do processo, foram emergindo compreensões de que a noção de inclusão extrapola a questão escolar da deficiência e que é possível - e necessário - construir um trabalho educacional a partir de uma ótica inclusiva no campo.

Para melhor discutir esse processo que tomou diferentes formas e proporcionou o início de uma construção de possibilidades acerca de uma prática de educação inclusiva na educação do campo, optamos por trazer algumas falas que nos mobilizaram e que demonstram as diferentes etapas vivenciadas durante o encontro. Ao problematizar os benefícios e malefícios de uma educação inclusiva em uma sala de aula superlotada, os estudantes manifestaram haver mais malefícios:

Já é difícil para a gente, imagina então para um aluno que tem um certo grau de dificuldade, daí se a gente tá falando de inclusão, se a professora não é qualificada para especialmente fazer isso, porque na verdade ela não é preparada. Se ele for surdo, por exemplo, ela tem que dar mais cuidado para ele, né? Trabalho junto, né?

Assim, se tratando assim da nossa realidade no campo, porque geralmente falta professor. Assim, professor de português que dá matemática, porque tem deficiência para professores nas suas próprias áreas, porque assim, lá, não é querer tratar diferente, né, no sentido assim, mas precisa de um cuidado, precisa de uma formação assim para trabalhar com crianças assim na nossa realidade não tem.

Eu vejo os dois lados, os malefícios e os benefícios. No sentido de politicamente mais semelhante é um benefício para 
democratizar o ensino e a inclusão, mas vendo o lado do maleficio, por exemplo, não dando condições, o professor não tem qualificação para trabalhar, além da má qualificação, as coisas mais físicas não são preparadas. Benefícios, só o político, porque a democratização da inclusão tá sendo vista, mas a desmoralização das escolas, que não tão conseguindo atender a qualidade de ensino para alunos que são normais e para os que não são normais.

No início da oficina, a postura observada era de incerteza e insegurança frente ao problema, por meio de críticas em relação ao Estado e isenção da responsabilidade de realizar uma educação do campo inclusiva. Esta postura foi justificada pela inexistência de uma formação adequada, bem como pela estrutura física que não atende às demandas de estudantes e professores. Os estudantes pareciam encontrar dificuldades em, a partir da crítica, dar prosseguimento a outras reflexões. Apesar de a crítica ser fundamental para um processo de transformação, entendemos que quando ficamos restritos a ela, podemos nos impedir de buscar novas possibilidades. Embora entendamos que essa postura possa refletir a cultura de falta de diálogo com a prática dos professores, desencorajando a criatividade e a implicação do professor como sujeito, bem como vinculando o conhecimento simplesmente ao saber-fazer (FURLANETTO, 2011; MARTINS, 2014), este também é o momento de tomada de consciência que permite a problematização e construção coletiva de conhecimento (ARAÚJO, 2011) a partir de uma estratégia alternativa que faz uma ruptura com o saber-poder, iniciando a construção de conhecimento pautada pelo saber do afeto na busca pela verdade e por novas soluções (AGUIAR, 2012). 0 foco na deficiência também vale ser frisado, uma vez que pode se tornar um impeditivo de práticas verdadeiramente inclusivas. Ao pensar o estudante surdo apenas como uma pessoa com deficiência auditiva, ele deixa de ser visto como um sujeito de possibilidades para ser uma deficiência que atrapalha o processo educativo (VYGOTSKY, 1997). Ainda assim, as especificidades da pessoa surda precisam ser respeitadas, principalmente no que concerne à sua comunicação, fato que foi apontado quando uma das pesquisadoras, buscando dar continuidade ao processo de reflexão dos estudantes, questionou sobre o que seria considerado um professor habilitado e o que seria necessário para tal:

Estudante 1- Vou dar um exemplo, por exemplo, um professor que tem habilidade para falar linguagem de sinais...

Pesquisadora - Tá, então cada uma das escolas deveria ter um professor habilitado para cada uma das necessidades específicas? Como a colega trouxe, uma escola especial, uma APAE novamente, seria uma instituição como uma APAE, para surdos, seria essa a solução então?

Estudante 2 - Eu acho que voltar a APAE, por exemplo, não seria inclusão.

Estudante 1 - Poderia ser em outro período, ir de manhã e à tarde, de manhã ele ia aprender bem e à tarde incluindo ele também. Num período APAE e no outro período inclusão também com outros colegas que não são portadores de necessidades especiais.

Pesquisadora - Na experiência de vocês, o que mais poderia ser feito?

Estudante 3 - A gente não tinha nenhuma política social até 2011, a escola não tem sequer como fazer. Vamos buscar os recursos, vamos trabalhar, conscientizando, trabalhando com os pais: Olha, a inclusão é assim, seu filho tá incluso, mas agora quero saber como de fato ele pode ser incluso, de fato, não incluso só fisicamente. Foi o que eu coloquei no início, a democratização e a inclusão é fácil falar, agora... Fazer acontecer, 
é que é o nosso desafio, na nossa realidade... E lutar por essa causa.

Estudante 4 - A gente descobriu que essas pessoas que têm dificuldade de aprender, a gente vê um modo de descobrir um ponto que [ela] gosta de trabalhar. Por exemplo, um aluno não gosta de escrever um ditado, de copiar do quadro, ou não gosta de fazer uma redação, tem de descobrir se ele gosta de futebol, fazer uma redação sobre futebol, se ele gosta de andar a cavalo, tem que fazer uma redação sobre um dia que andou a cavalo, descobrir o esporte, o que agrada ele. Acho que também pode ser um caminho para desenvolver aos poucos as pessoas que tem dificuldade. Acho que é isso.

Como todo processo, este que estamos detalhando também está em permanente construção, em um devir constante. Dado isso, é importante colocar e discutir aqui que não aconteceu um contínuo crescente em direção ao que se considera usualmente como o esperado em uma situação de pesquisa. Não buscamos atingir como resultado uma fala homogênea e doutrinada sobre a importância e o caráter imprescindível de uma educação do campo inclusiva. 0 objetivo reside na tentativa de melhor compreensão do processo vivido e, no caso, as falas finais foram fundamentais. Essas eram fruto de desestabilizações, ânsias e medos dos estudantes, nos mobilizaram e nos levaram à reflexão, colaborando imensamente com a construção de conhecimento sobre uma educação do campo inclusiva. Uma dessas manifestações trouxe à tona questões bastante importantes sobre o tema e foi um dos definidores da necessidade de aprofundar aqui as questões trazidas:

Esse momento, essa aula, aula, viu? [risos]. Essa aula cria uma esperança, cria uma expectativa muito forte. Porque, por exemplo, eu olho pra você que já tem um preparo nessa área e tudo mais e eu fico esperando que você vá tirar o coelho da cartola e resolver os nossos problemas, sabe? Eu penso: Não, ela tá pegando tudo, depois ela vai pegar tudo e dizer assim: tá aqui, a fórmula mágica. E às vezes eu olho pra você e falo assim: Não, ela tá igual, no mesmo nível que a gente, ela tá colhendo informação pra formar a opinião dela. E daí eu falo: Tamo perdido!

Percebemos aí alguns aspectos que possibilitam as seguintes discussões: primeiro, a ideia de que há a necessidade de que o conhecimento do saber-fazer (MARTINS, 2014) seja necessariamente transmitido por alguém que o detém mesmo sem fazer parte da realidade da educação do campo. Nota-se uma posição que desconsidera a existência de um processo epistemológico de construção de conhecimentos em diferentes contextos, no caso, o campo. Nessa concepção, os conhecimentos são existentes $a$ priori e produzidos apenas por especialistas que se encarregam de disseminá-lo (OLIVEIRA, 2012). A partir desse fato e considerando as falas dos participantes da pesquisa, levantamos a hipótese de que a expectativa por respostas, relatada acima, esteja relacionada a essa concepção de que apenas o especialista é detentor de conhecimento, sem que, no caso mencionado, futuros professores de escolas do campo possam contribuir para a construção desse saber. Percebemos ainda certa hesitação por parte dos estudantes em relação à postura da pesquisadora que se propôs sair do modelo educacional tradicional de aula, sem respostas prontas e conhecimentos previamente formulados.

Em segundo lugar, a necessidade de que isso se faça em um ambiente tradicional que chamamos de aula, demonstra o engessamento do sistema educacional que não permite vislumbrar outras possibilidades de ação dentro de uma instituição de ensino. Vale frisar que esse encontro foi realizado em uma parte externa às salas de aula, mas ainda assim persistiu a noção de aula e o formato específico que essa aula deve atender. Uma discussão pertinente neste caso 
é o papel de submissão acadêmica que existe entre estudantes provenientes do campo e os professores e / ou pesquisadores provenientes de contextos urbanos e, mais ainda, com um percurso na universidade, em que se observa a tendência de centralização do conhecimento em si mesma (ARAÚJO, 2011). Munarim (2006) discute a concepção social difundida de que o campo é inferior e insuficiente em relação à cidade. 0 mesmo ocorre com o conhecimento, que deve vir da cidade e ser depositado (FREIRE, 1983) nos estudantes campesinos. Acreditamos que o conhecimento proveniente do campo é não só importante, mas fundamental para se construir uma educação do campo inclusiva. Ao longo da discussão novas reflexões foram emergindo a partir desse debate, como podemos perceber nas falas seguintes:

É um desafio, mas a educação é importante para todos e todas. E muitos de nós temos diferenças, deficiências que talvez não sejam físicas, mas são deficiências que também lidam no dia a dia.

Muita gente tava esperando por uma resposta, mas na verdade nós é que temos que construir esse processo e essa informação para estarmos preparados.

Ao mesmo tempo em que esse encontro traz essas trocas de experiências, mas também traz muitas dúvidas. [...] São dúvidas que a gente não vai conseguir responder de imediato, como você disse, que a gente vai construir aos poucos. Mas tudo é muito gratificante. Se a gente conseguir sair daqui com o mínimo, o que o tempo permitir que a gente trabalhe. [...] Mas isso com certeza vai fazer muita diferença nas nossas comunidades quando a gente chegar em sala de aula e trabalhar a inclusão.

A inclusão, ela irá começar a partir de nós, porque como não foi fácil ter escolas itinerantes, também não é fácil ter essa inclusão. Ela vai começar a partir de nós, a partir do que a gente for cobrar, receber essas pessoas e cobrando juntamente com os pais e com a própria escola.

\section{Considerações finais}

Ao analisar todas as reflexões expostas, ressalta-se o caráter transitório e em constante modificação que esta construção em forma de devires proporciona. 0 debate coletivo, a partir de alguns elementos apresentados e diversos outros trazidos pelos participantes, proporcionou uma importante reflexão sobre seus papéis como sujeitos ativos do processo de construção de possibilidades para uma educação do campo inclusiva.

Um espaço de construção coletiva na formação de professores nos cursos de licenciatura em educação do campo pode colaborar para que seja problematizada e construída uma possibilidade real e contextualizada de uma educação do campo inclusiva. Essa proposta de formação reconhece e estimula as experiências e os conhecimentos próprios dos seus participantes que, como a própria nomenclatura sugere, participam ativamente do processo de construção de conhecimento.

Apesar de ser extremamente necessário que o Estado dê condições para que todos e todas tenham a garantia do direito à educação, frisamos aqui a importância de que o(a) professor(a) se reconheça como capaz de exercer uma prática de educação inclusiva. É fundamental que não se outorguem aos profissionais especializados a responsabilidade total do desenvolvimento de um estudante que apresenta desenvolvimento atípico. Entender a educação do campo como uma educação do campo inclusiva é perceber que todas as atitudes tomadas em sala de aula devem ser inclusivas, sem um foco específico em um estudante que recebeu um diagnóstico de deficiência. Isso poderá acrescentar muito ao desenvolvimento do campo, uma vez que possibilita a qualidade da educação para todos. 
Reconhecer-se como produtor de conhecimento pode auxiliar no desempenho de um papel ativo quando acontecer a vivência da situação. Além disso, valorizar o conhecimento da mulher e do homem do campo tem um papel político importante, que fortalece não apenas os sujeitos, mas o próprio contexto, além de possibilitar a existência de referenciais e práticas específicas destinadas àquele espaço, produzidos por seus integrantes.
Por fim, reconhecemos que os participantes dessa pesquisa estão em um contexto de lutas e conquistas por direitos de inclusão por meio de uma articulação com o Estado que reconheça a legitimidade das reivindicações das populações do campo e atenda às demandas deste contexto. A nossa proposta visou a agregar a essa luta um espaço de reflexão e produção de conhecimento que poderá dar subsídios para que esse processo continue.

\section{Referências}

AGUIAR, Kátia. Práticas de formação e a producão de políticas de existência. Psicologia e Sociedade, Belo Horizonte, v. 24, 2012. Disponivel em: <http://www.scielo. br/scielo.php?script=sci_arttext\&pid=S0102-71822012000400010\&lng=en\&nrm=i so>. Acesso em: 27 jul. 2015.

ARAÚJO, Mairice da Silva. Pensando práticas e saberes na formação continuada de professores/as. In: Associação Nacional de Pesquisadores em Educação (Ed.). Práticas pedagógicas, linguagem e mídias: desafios à pós graduação em educação em suas múltiplas dimensões. Rio de Janeiro: ANPEd, 2011. p. 193-205.

BRASIL. Ministério da Educação. Diretrizes nacionais para a educação especial na educação Básica. Brasilia, DF: MEC, 2001a. Disponível em: <http://portal.mec.gov.br/arquivos/pdf/diretrizes.pdf>. Acesso em: 05 nov. 2015.

BRASIL. Lei $n^{\circ} 10.172$ de janeiro de 2001. Aprova o Plano Nacional de Educação e dá outras providências. Brasília, DF: [s. n.], 2001b. Disponível em: <http://www.planalto.gov.br/ccivil_03/leis/leis_2001/110172.htm>. Acesso em: 05 nov. 2015.

BRASIL. Lei ${ }^{\circ} 12.796$ de 4 de abril de 2013. Estabelece as leis de diretrizes e bases da educação nacional atualizada. Brasilia, DF: [s. n.], 2013. Disponível em: <http://www.planalto.gov.br/ccivil_03/Leis/L9394.htm>. Acesso em: 05 nov. 2015.

BRASIL. Constituição da República Federativa do Brasil de 1988. Brasília, DF: [s. n.], 1998. Disponível em: <http://www. planalto.gov.br/CCIVIL_03/Constituicao/Constitui\%C3\%A7ao.htm>. Acesso em: 05 nov. 2015.

BRAÚNA, Rita de Cássia de Alcântara. 0 papel da formação inicial na constituição das identidades profissionais de alunas do curso de pedagogia. Rio de Janeiro: ANPEd Sudeste, 2011. (Coleção Anpep Sudeste 2011, Livro 2).

CALDART, Roseli Salete. Educação em movimento: formação de professores e professoras no MST. Petrópolis: Vozes, 1997.

CALDART, Roseli Salete. Educação do campo. In: CALDART, Roseli Salete et al. (Org.). Dicionário de educação do campo. Rio de Janeiro: São Paulo: Escola Politécnica de Saúde Joaquim Venâncio Expressão Popular, 2012.

CÂMARA DOS DEPUTADOS. Projeto de Lei: plano nacional de educação para o decênio 2011-2020, Brasília, DF: [s. n.], 2012. Disponível em: <http://www.camara.gov.br/sileg/integras/831421.pdf>. Acesso em: 05 nov. 2015.

CIASCA, Sylvia Maria; RODRIGUES, Sonia das Dores; CINTRA, Gilcineia Maria Silveira. Inclusão escolar: há coesão nas expectativas de pais e professores. Psicopedagogia: Revista da Associação Brasileira de Psicopedagogia, 26 (79), 55-64, 2009.

COELHO, Cristina Madeira. Inclusão escolar. In: MACIEL, Diva Albuquerque; BARBATO, Silviane (Org.). Desenvolvimento humano, educação e inclusão escolar. Brasília, DF: UnB, 2010. p. 55-72.

COSTA, Alexandre. Heráclito: fragmentos contextualizados. Rio de Janeiro: DIFEL, 2002.

COSTA, Vanderlei Balbino. A concepção de professores frente à inclusão escolar na diversidade. In: SIMPÓSIO INTERNACIONAL: 0 estado e as políticas educacionais no tempo presente. Disponível em: <http://www.simposioestadopoliticas. ufu.br/imagens/anais/ pdf/BC01.pdf>. Acesso em: 3 mar. 2012. 5., 2008, Uberlândia. V Simpósio... Uberlândia [s.n], 2008.

DELEUZE, Gilles; GUATTARI, Félix. Mil platôs: capitalismo e esquizofrenia. São Paulo: Editora 34, 2008.

FREIRE, Paulo. Pedagogia da autonomia. São Paulo: Paz e Terra, 2007.

FREIRE, Paulo. Pedagogia do oprimido. Rio de Janeiro: Paz e Terra, 1983.

FREIRE, Paulo. Pedagogia dos sonhos possíveis. São Paulo: Unesp, 2001. 
FREIRE, Paulo; GUIMARÃES, Sérgio. A África ensinando a gente: Angola, Guiné-Bissau, São Tomé e Príncipe. São Paulo: Paz e Terra, 2003.

FURLANETTO, Ecleide Cunico. A formação como possibilidade de conhecimento e transformação de matrizes pedagógicas. In: Associação Nacional de Pesquisadores em Educação (Ed.). Formação de professores, culturas: desafios à pós-graduação em educação em suas múltiplas. Rio de Janeiro: ANPẼd Nacional, 2011. p. 107-118.

GONZÁLEZ REY, Fernando. Pesquisa qualitativa e subjetividade: os processos de construção da informação. São Paulo: Pioneira Thomson Learning, 2005.

GONZÁLEZ REY, Fernando. Psicoterapia, subjetividade e pós-modernidade. São Paulo: Thomsom, 2007.

GONZÁLEZ REY, Fernando. Sujeito e subjetividade: uma aproximação histórico-cultural. São Paulo: Thomson Learning, 2003.

GUATTARI, Félix; ROLNIK, Suely. Micropolítica: cartografias do desejo. Petrópolis: Vozes, 2005.

HARPER, Babette. et. al. Cuidado, escola! Desigualdade, domesticação e algumas saídas. São Paulo: Brasiliense, 1980.

MARSCHNER, Walter. Lutando e ressignificando o rural em campo: notas epistemológicas. Interações, 12(1), 41-52, 2011.

MARQUES, Suely Moreira. Pensar e agir na inclusão escolar de crianças com necessidades educacionais especiais decorrentes de uma deficiência, a partir de referenciais freirianos: rupturas e mutações culturais na escola brasileira. Tese, USP, Universitè Lumiére Lyon, São Paulo, 2007.

MARTINS, João Batista. A formação de professores no âmbito da abordagem multirreferencial. Psicologia Escolar e Educacional, Maringá, v. 18, n. 3, p. 467-476, 2014. Disponível em: <http://www.scielo.br/scielo.php?script=sci_arttext\&pid =S1413-8557201400030046 7\&lng=en\&nrm=iso >. Acesso em: 05 nov. 2015.

MUNARIM, Antonio. Elementos para uma política pública de educação do campo. In: MOLINA, Mônica. (Org.). Educação do campo e pesquisa: questões para reflexão. Brasília, DF: Ministério do Desenvolvimento Agrário, 2006. p. 15-26.

OLIVEIRA, Inês Barbosa de. Contribuições de Boaventura de Sousa Santos para a reflexão curricular: princípios emancipatórios e currículos pensadospraticados. E-curriculum, São Paulo, v. 8, n.2, p. 1-22, 2012.

OLIVEIRA, Lia Maria Teixeira de; CAMPOS, Marília. Educação básica do campo. In: CALDART, Roseli Salete et al. (Org.). Dicionário da educação do campo. Rio de Janeiro: São Paulo: Escola Politécnica de Saúde Joaquim Venâncio; Expressão Popular, 2012.

PASSOS, Eduardo; BENEVIDES DE BARROS, Regina. A cartografia como método de pesquisa-intervenção. In: PASSOS, Eduardo; KASTRUP, Virgínia; ESCÓSSIA, Liliana (Org.). Pistas do método da cartografia: pesquisa intervenção e produção de subjetividade. Porto Alegre: Sulina, 2009. p. 17-31.

PASSOS, Eduardo; KASTRUP, Virgínia; ESCÓSSIA, Liliana da. Pistas do método da cartografia: pesquisa - intervenção e produção de subjetividade. Porto Alegre: Sulina, 2009.

PULINO, Lúcia Helena Cavasin Zabotto. Espaço Aion: a filosofia como espaço de reflexão na comunidade. Childhood \& Philosophy, v. 3, n. 09 (12), 2007.

PULINO, Lúcia Helena Cavasin Zabotto. Filosofia, pegagogia e psicologia: a formação de professores e a ética do cuidado de si. In: KOHAN, Walter Omar (Org.) Devir-criança da filosofia: infância da educação. Belo Horizonte: Autêntica, 2010. p. 153-164.

PULINO, Lúcia Helena Cavasin Zabotto; HORTA, Viviane. Espace Aion: une espace/temps de philosopher avec groupes hétérogènes. In: Journée Mondiale de la philosophie - gèmes rencontres sur les Nouvelles Pratiques Philosophiques. Paris. Nouvelles Pratiques Philosophiques: Et si I'on philosophait autrement?. Paris: UNESCO/UPEC Université Paris Est - Créteil, 2009.

ROMAGNOLI, Roberta Carvalho. A cartografia e a relação pesquisa e vida. Psicologia e Sociedade, v. 21, n. 2, 2009. Disponível em: <http://www.scielo.br/scielo.php?script=sci_arttext \&pid=S010271822009000200003\&lng=pt \&nrm =iso>. Acesso em: 12 jun. 2012.

SANT'ANA, Izabella Mendes. Educação inclusiva: concepções de professores e diretores. Psicologia em Estudo, v. 10, n. 2, p. 227-234, 2005.

SANTOS, Clarice Aparecida dos. Educação do campo e políticas públicas no Brasil: o protagonismo dos movimentos sociais do campo na instituição de políticas públicas e a licenciatura em eEducação do campo na UnB. Brasília, DF: Liber Livro: UnB, 2012. 
SOUZA, Maria Antônia de. Educação do campo: políticas, práticas pedagógicas e produção científica. Educação \& Sociedade, v. 29, n. 105, p. 1089-1111, 2008.

UNESCO. Final report: World Conference on Education for All - Meeting basic learning needs. Jomtien (Tailândia), 1990. Disponível em: <http://unescodoc.unesco.org/images/0009/000975/097551e.pdf>. Acesso em: 10 out. 2013.

UNESCO. The Salamanca statement and framework for action on special needs education,1994. Disponível em: <http://www. unesco.org/education/pdf/SALAMA_E.PDF>. Acesso em: 10 out. 2013.

UNB. Projeto político pedagógico do curso de licenciatura em educação do campo. Disponível em: <http://www.fup.unb.br/ images/stories/media/Ensino/ppp\%20ledoc.pdf>. Acesso em: 31 mar. 2015.

VYGOTSKY, Lev Semenovich. Obras escogidas. tomo V. Madrid: Visor, 1997.

Recebido em: 12.01.2015

Aprovado em: 14.04.2015

Juliana Crespo Lopes foi professora da Faculdade de Educação da Universidade de Brasília, psicóloga pela Universidade Federal de Santa Catarina, mestre em Psicologia pela Universidade de Brasília.

Lucia Helena Cavasin Zabotto Pulino é professora adjunta do Instituto de Psicologia, da Universidade de Brasília. Psicóloga pela Universidade de São Paulo (USP), mestre em lógica e filosofia da ciência pela Universidade Estadual de Campinas (Unicamp), doutora em filosofia pela Unicamp e com estágio pós-doutoral em filosofia na Université Paris 8.

Mariana Barbato é psicóloga graduada em 2013 na Universidade de Brasília. Tem experiência em atendimento clínico há quatro anos e experiência em docência na educação infantil pela Associação Pró-educação Vivendo e Aprendendo.

Regina Lucia Sucupira Pedroza é professora adjunta do Instituto de Psicologia da Universidade de Brasília. É professora nas pós-graduações de processos de desenvolvimento humano e saúde e direitos humanos e cidadania da Universidade de Brasília. 